\title{
The Mycobacterial Cell Wall-Peptidoglycan and Arabinogalactan
}

\author{
Luke J. Alderwick, James Harrison, Georgina S. Lloyd, and Helen L. Birch \\ Institute of Microbiology and Infection, School of Biosciences, University of Birmingham, Birmingham \\ B15 2TT, United Kingdom \\ Correspondence: I.alderwick@bham.ac.uk
}

\begin{abstract}
The mycobacterial bacillus is encompassed by a remarkably elaborate cell wall structure. The mycolyl-arabinogalactan-peptidoglycan (mAGP) complex is essential for the viability of Mycobacterium tuberculosis and maintains a robust basal structure supporting the upper "myco-membrane." M. tuberculosis peptidoglycan, although appearing to be unexceptional at first glance, contains a number of unique molecular subtleties that become particularly important as the TB-bacilli enters into nonreplicative growth during dormancy. Arabinogalactan, a highly branched polysaccharide, serves to connect peptidoglycan with the outer mycolic acid layer, and a variety of unique glycolsyltransferases are used for its assembly. In this review, we shall explore the microbial chemistry of this unique heteropolysacchride, examine the molecular genetics that underpins its fabrication, and discuss how the essential biosynthetic process might be exploited for the development of future anti-TB chemotherapies.
\end{abstract}

\section{THE MYCOBACTERIAL CELL WALL-PEPTIDOGLYCAN AND ARABINOGALACTAN}

$T^{\text {h }}$ he remarkable molecular complexity of the mycobacterial cell wall is a particularly distinguishing feature that set Mycobacterium species apart from the majority of other prokaryotes. Although classified as gram-positive organisms, their envelopes do in fact share notable features with Gram-negative cell walls, such as an outer permeability barrier acting as a pseudo-outer membrane (Minnikin 1982; Brennan and Nikaido 1995). Much of the early structural definition of the cell wall was conducted in the 1960s and 1970s (Adam et al. 1969; Petit et al.
1969; Lederer et al. 1975) and later continued by Minnikin, who in 1982 proposed the currently accepted structural model for the cell wall architecture (Minnikin 1982). The mycolyl-arabinogalactan-peptidoglycan (mAGP) complex, as it is commonly termed, represents the cell wall core structure that encompasses the mycobacterial bacilli.

\section{Structural Features of Mycobacterial Peptidoglycan}

Peptidoglycan (PG) is a complex macromolecular structure situated on the outside of the plasma membrane of almost all eubacteria (Schleifer and Kandler 1972; van Heijenoort

Editors: Stefan H.E. Kaufmann, Eric J. Rubin, and Alimuddin Zumla

Additional Perspectives on Tuberculosis available at www.perspectivesinmedicine.org

Copyright (C) 2015 Cold Spring Harbor Laboratory Press; all rights reserved; doi: 10.1101/cshperspect.a021113

Cite this article as Cold Spring Harb Perspect Med 2015;5:a021113 
L.J. Alderwick et al.

2001). Its mesh-like arrangement confers rigidity to the cell, allowing it to withstand osmotic pressure maintaining cell integrity and cellular shape. Relatively little is known about Mycobacterium tuberculosis PG synthesis, although it is generally assumed to be analogous to that of Escherichia coli (van Heijenoort 2001), also being classified as Al $\gamma$ according to the classification system of Schleifer and Kandler (1972). Mycobacterial PG forms the basal layer of the mAGP complex and is composed of alternating $N$-acetylglucosamine (GlcNAc) and modified muramic acid (Mur) residues, linked in a $\beta(1 \rightarrow 4)$ configuration (Lederer et al. 1975). Unlike E. coli PG, the muramic acid residues in both M. tuberculosis and Mycobacterium smegmatis contain a mixture of $N$-acetyl and $N$-glycolyl derivatives, whereby the $N$-acetyl function has been oxidized to a $N$-glycolyl function to form MurNGly (Mahapatra et al. 2000, 2005; Raymond et al. 2005). Although the precise function of the $N$-glycolyl modifications is yet to be elucidated, it has been hypothesized that these additional glycolyl-containing residues might have the potential for additional hydrogen bonding interactions, strengthening the mesh-like structure of the PG layer (Brennan and Nikaido 1995), as well as possibly protecting the organism from degradation via lysozyme (Chatterjee et al. 1991). Tetrapeptide side chains consisting of L-alaninyl-D-isoglutaminylmeso-diaminopimelyl-D-alanine are crosslinked with identical short peptides of neighboring glycan chains (Petit et al. 1969). These cross-links include the expected $3 \rightarrow 4$ mesodiaminopimelic acid (DAP) and D-alanine bond that is common to most prokaryotes, but also a high degree of $3 \rightarrow 3$ bonds between two residues of DAP (Ghuysen 1968; Wietzerbin-Falszpan et al. 1970). The proportion of cross-linking in Mycobacterium species is 70\%-80\% (Matsuhashi 1966), significantly more so than E. coli, with only 50\% (Vollmer and Holtje 2004). An additional deviation from E. coli PG is the use of the muramic acid residues as attachment sites for the galactan domain of the arabinogalactan, whereby $6-\mathrm{OH}$ of some of the muramic acid residues form a phosphodiester bond and are linked to the
$\alpha$-L-rhamnopyranose- $(1 \rightarrow 3)$ - $\alpha$-D-GlcNAc $(1 \rightarrow \mathrm{P})$ linker unit of AG (McNeil et al. 1990).

One model proposed for the three-dimensional topology of the mAGP complex, consistent with the traditional models of PG architecture (Ghuysen 1968; Brennan and Nikaido 1995), suggests that the PG and the galactan moiety run parallel to the plasma membrane. However, an opposing model put forward by other modeling studies predicts that the PG and the AG polymers may in fact be coiled and are thus orientated perpendicular to the plane of the plasma membrane (Dmitriev et al. 2000, 2003). Minnikin et al. (2002) proposed that both AG and LAM polymers form coiled strands and integrate with the basal PG layer. Interestingly, a study by Meroueh et al. (2006) presented compelling evidence in the form of nuclear magnetic resonance (NMR) data that suggests that the PG glycan strand is orthogonal to the plane of the membrane; thus, the overall three-dimensional structure and topology remain open to debate.

\section{Biosynthesis of Mycobacterial Peptidoglycan}

\section{Cytoplasmic Steps of Peptidoglycan Intermediate Metabolism}

The biosynthesis of PG begins within the cytoplasm of all bacteria that contain a murein sacculus, and the activated sugar nucleotide UDPGlcNAc is usually considered to be the "start point" of PG anabolism. UDP-GlcNAc is synthesized from D-fructose-6-phosphate in four steps and requires three enzymes. GlmS is an aminotransferase that converts D-fructose-6phosphate to D-glucosamine-1-phosphate, and although a clear ortholog is present in $M$. tuberculosis, there has been no investigation of this gene or protein to date (Durand et al. 2008). GlmM is a mutase enzyme that converts Dglucosamine-1-phosphate to D-glucosamine-6phosphate and has been shown to be an essential gene in M. smegmatis ( Li et al. 2012). Indeed, the conversion of D-glucosamine-6-phosphate to Dglucosamine-1-phosphate is unique to prokaryotes and is considered a potential drug target $(\mathrm{Li}$ et al. 2011). GlmU is a bifunctional enzyme that 
carries out both acetylation and uridylation reactions, ultimately forming UDP-GlcNAc (Jagtap et al. 2012, 2013). The carboxy-terminal domain of GluU is responsible for catalyzing acylation of D-glucosamine-6-phosphate whereas the amino-terminal domain catalyzes uridylation of $N$-acetylglucosamine-1-phosphate. GlmU has been shown to be an essential gene in M. smegmatis (Zhang et al. 2008). Interestingly, a single threonine residue within the carboxyterminal domain of GlmU is phosphorylated by the serine/threonine protein kinase $\mathrm{PknB}$, resulting in a modulation of GlmU acetyltransferase activity (Parikh et al. 2009).

UDP-MurNAc is formed from UDPGlcNAc in a two-step process involving the catalytic activities of two enzymes, MurA and MurB. MurA is a UDP-GlcNAc enolpyruvyl transferase that catalyzes the transfer of enolpyruvate from phosphoenoylpyruvate to the 3position of the $\mathrm{N}$-acetylglucosamine moiety of UDP-GlcNAc, liberating inorganic phosphate in the process. Fosfomycin is an analog of phosphoenoylpyruvate and it inhibits MurA by alkylating an active site cysteine residue (Kim et al. 1996). However, although fosfomycin is considered to be a broad-spectrum antibiotic, it has no ready utility as an antitubercular drug. M. tuberculosis is inherently resistant to fosfomycin because of the presence of an aspartic acid in place of the aforementioned cysteine, which usually confers sensitivity to the drug (De Smet et al. 1999). MurB is a reductase that uses NADPH as an electron donor to convert the enolpyruvate moiety to D-lactoyl, thus delivering UDP-MurNAc as a final product. To date, the investigation of MurB from mycobacteria has been limited to in silico homology modeling and molecular dynamics simulations (Kumar et al. 2011).

The intracellular ATP-dependent muramic acid ligase enzymes, MurC-MurF, work consecutively to synthesize UDP- $N$-acetylmuramyl pentapeptide and UDP- $N$-glycolylmuramyl pentapeptide from either UDP-MurNAc or UDPMurNGlyc, respectively. M. tuberculosis UDPMurNGlyc is initially generated by hydroxylation of the methyl group of the MurNAc moiety of UDP-MurNAc (Gateau et al. 1976; Essers and
Schoop 1978). Conversion of UDP-MurNAc to UDP-MurNGlyc involves a monooxygenase encoded by the namH gene (Raymond et al. 2005). Chemical analysis of the nucleotidelinked PG intermediates from M. tuberculosis strongly suggests that this pool of metabolites is composed of a mixture of both MurNAc and MurNGlyc subtypes, in which the proportion of MurNAc precursors is heavily suppressed by the presence of D-cycloserine but not vancomycin (Mahapatra et al. 2005). The UDP-MurNGlyc and UDP-MurNAc intermediates are then perpetuated throughout the PG pathway by the successive additions of Lalanine (MurC), D-glutamate (MurD), mesoDAP (MurE), and D-alanyl-D-alanine (MurF), a unique prokaryotic pathway, which has been extensively reviewed by other investigators (Barreteau et al. 2008). The Mur ligases C-F share a common mechanism whereby the carboxyl group appended to the UDP substrate is activated by phosphorylation with ATP, generating ADP. The UDP-substrate phospho-intermediate is then attacked by an amino acid or dipeptide specific to the ligase catalyzing the reaction, resulting in extension by aminoacylation of the UDP precursor and the expulsion of inorganic phosphate (Falk et al. 1996; Bouhss et al. 1999). Both M. tuberculosis and Mycobacterium leprae MurC orthologs have been shown to be capable of ligating both L-alanine and L-glycine to UDPMurNAc (Mahapatra et al. 2000). Apart from MurC, the only other ATP-dependent Mur ligase that has been biochemically characterized is MurE (Basavannacharya et al. 2010a,b).

Several other enzymes play vital roles in the cytoplasmic assembly of PG, two of which are the Alr and Ddl proteins that provide L-alanine racemase activity and D-alanine:D-alanine ligase activity, respectively (Feng and Barletta 2003). Several recent biochemical studies have provided comprehensive molecular insight into how D-cycloserine (currently used as a secondline anti-TB agent) inhibits the Ddl enzyme (Prosser and de Carvalho 2013a,b). In this regard, a number of high-throughput screening studies have identified Alr as being an equally interesting drug target (Anthony et al. 2011; Lee et al. 2013). 
L.J. Alderwick et al.

Polyprenyl phosphates play a crucial role in prokaryotic cell wall biosynthesis, providing a hydrophobic lipid anchor that enables cell envelope biosynthesis to occur while being tethered to the cytoplasmic membrane. In mycobacteria, MurX (usually termed MraY in other prokaryotes) is an integral membrane protein that transfers the phospho-MurNAc-pentapeptide to a decaprenol phosphate lipid. The result is the displacement of the UDP nucleotide moiety with a decaprenyl lipid carrier, thus forming lipid I from Park's nucleotide. Although the molecular genetics or biochemistry of MurX has not been studied in detail, it appears that MurX from M. smegmatis is capable of incorporating the muramyl-pentapeptide from both UDP- $N$-acetylmuramyl pentapeptide and UDP-N-glycolylmuramyl pentapeptide precursors with equal efficiency (Chen et al. 2013). MurG is a GT-B glycosyltransferase that uses UDP-GlcNAc as a substrate to form a $\beta(1 \rightarrow$ 4) glycosidic bond between GlcNAc and either the MurNAc or MurNGlyc sugar of lipid I. MurG from M. tuberculosis has been shown to be able to complement a murG-deficient strain of E. coli (Jha et al. 2012), and because of the essential nature of MurG, it is a target for the development of new antibacterial agents (Trunkfield et al. 2010). MurG marks the final "step" in the cytoplasmic pathway of PG biosynthesis, and its product is a cell wall intermediate termed lipid II.

\section{The Latter Stages of Peptidoglycan Assembly}

The cytoplasmic membrane presents a physical barrier that separates the cytoplasm from the outer periplasmic space of the mycobacterial cell, as well as a thermodynamic hurdle that must be overcome by numerous cell wall intermediates that are destined for deposition in the mycobacterial envelope. Lipid II separates the cytoplasm from the outer periplasmic space of the mycobacterial cell. Several biochemical and molecular genetic investigations in other nonmycobacterial prokaryotes have identified both MurJ and FtsW proteins as being candidate proteins that translocate lipid II across the bacterial cytoplasmic membrane (Ruiz 2008; Mohammadi et al. 2011; Butler et al. 2013; Mohamed and Valvano 2014). FtsW belongs to the shape, elongation, division, and sporulation (SEDS) family of proteins, all of which are integral membrane proteins involved in translocation of molecules across the cytoplasmic membrane. Interestingly, RodA is also a member of the SEDS family, and a recent study has shown that this protein also contributes lipid II flippase activity as well as having a direct interaction with the polar growth organizing protein, DivIVA (Sieger et al. 2013).

Two proteins, PonA1 and PonA2, encoded by $R v 0050$ and $R v 3682$, respectively, are bifunctional penicillin-binding proteins that carry out both transglycoylase and transpeptidase enzymatic reactions, both of which use lipid II as a substrate. Studies on PonA1 from M. smegmatis have shown that apart from it being necessary for maintaining cell shape, viability, and integrity, this enzyme is also required for synergistic regulation of $\mathrm{PG}$ hydrolysis by interacting with the RipA-RpfB complex, a lytic transglycosylase and endopeptidase, respectively (Hett et al. 2010). PonA2 has also been attributed to having an important role in maintaining cell shape, integrity, and adaptation of $M$. tuberculosis into dormancy (Patru and Pavelka 2010). However, a recent biochemical and structural study of the PASTA domain from PonA2 has shown that this protein is unable to bind classical cognate ligands, such as muropeptides, $\beta$-lactams, or nascent PG (Calvanese et al. 2014).

$\mathrm{PBPa}$ and $\mathrm{PBPb}$ are two variants of the high-molecular-mass penicillin-binding proteins found in M. tuberculosis. PBPa is a class A penicillin-binding protein that plays an important role in the cell division process and maintenance of cell shape (Dasgupta et al. 2006). $\mathrm{PknB}$, a serine/threonine-specific protein kinase, has been shown to phosphorylate $\mathrm{PBPa}$ on two key threonine residues T362 and T437, the latter of which is crucial to enable full signal transduction-mediated control of this important cell wall process (Dasgupta et al. 2006). Interestingly, both $\mathrm{PBPa}$ and $\mathrm{PBPb}$ have been shown to directly interact with the cell division 
complex and septal formation machinery FtsZ, FtsQ, and CrgA (Plocinski et al. 2011).

Although the PG of actively replicating M. tuberculosis contains a network of classical $3 \rightarrow 4$ transpeptide bonds, PG from nonreplicating $M$. tuberculosis contains significantly more nonclassical $3 \rightarrow 3$ linkages. Thus, a significant molecular rearrangement must occur in the PG of M. tuberculosis as its shifts its mode of growth from one of propagation into one of dormancy. The M. tuberculosis genome encodes at least five nonclassical L,D-transpeptidases (Ldt), which are the enzymes responsible for generating $3 \rightarrow 3$ linkages between opposing stem peptides in mycobacterial PG. M. tuberculosis deficient in both LdtMt1 and LdtMt 2 activities shows an altered cell surface morphology and severely attenuates the growth and virulence of M. tuberculosis (Schoonmaker et al. 2014). Other biochemical studies have identified LdtM2 as being important for resistance to $\beta$ lactam antibiotics such as amoxicillin (Gupta et al. 2010) as well as carbapenems, and the structural basis for the inhibition of LdtMt 2 by meropenem has been elucidated (Kim et al. 2013; Li et al. 2013). The X-ray crystal structure of LdtMt1 has also been solved in the apo and meropenem-bound form, highlighting some subtle differences between these two variants of L,D-transpeptidases (Correale et al. 2013).

\section{ARABINOGALACTAN}

\section{Structural Features of Arabinogalactan}

Arabinogalactan (AG) is a heteropolysaccharide that is covalently tethered to $\sim 10 \%-12 \%$ of the muramic acid residues of PG via a phosphodiester bond (Amar and Vilkas 1973). Collectively, PG and AG form a huge macro polymer positioned between the cytoplasmic membrane and the outer mycolic acid layer of the TB bacilli. Early work showed that AG was composed predominantly of arabinose and galactose and constitutes $\sim 35 \%$ of the total mass of the cell envelope (Misaki and Yukawa 1966; Azuma et al. 1968; Kanetsuna 1968; Kanetsuna et al. 1969). Both arabinose and galactose sugars are present in the furanoid ring form, D-galactofuranosyl
(Galf) and D-arabinofuranosyl (Araf), which appear infrequently in nature (McNeil et al. 1987). A comprehensive characterization of oligomers generated from partial depolymerization of per-O-alkylated AG using gas chromatography-mass spectrometry (GC-MS), fast-atom bombardment-mass spectrometry (FAB-MS), and NMR spectroscopy resolved the detailed structure of the AG complex (McNeil et al. 1987; Daffé et al. 1990; McNeil et al. 1994; Besra et al. 1995). The molecular structure of AG can be segmented into three separate constituents: the linker unit (LU), galactan, and arabinan. Amar and Vilkas (1973) initially reported that AG is tethered to PG at intervals by a phosphodiester bond, supported by the presence of muramyl-6-phosphate in cell wall preparations from several mycobacterial species (Liu and Gotschlich 1967; Kanetsuna 1968). The chemical nature of this link was not answered until 20 years later when oligosaccharides containing Galf from the galactan domain were isolated along with rhamnose (Rha) residues (McNeil et al. 1990). The further discovery of the disaccharide L-Rhap- $(1 \rightarrow 3)$-DGlcNAc led to the conclusion that these constituents make up the linkage unit and the inference that the GlcNAc is directly attached to the 6position of a proportion of the muramyl residues of PG (McNeil et al. 1990). The D-galactan component of AG is composed of approximately 30 linear alternating $\beta(1 \rightarrow 5)$ and $\beta(1 \rightarrow 6)$ Galf residues (Amar and Vilkas et al. 1973; McNeil et al. 1987) and is attached to the rhamnosyl residue of the LU. Three tricosamer domains of D-arabinan, each composed of approximately 23 Araf residues, are affixed to the C-5 hydroxyl of $\beta(1 \rightarrow 6)$-linked Galf units (Besra et al. 1995) specifically to the 8 th, 10 th, and 12 th Galf residues of the galactan domain (Alderwick et al. 2005). The arabinan domain is a highly branched polysaccharide built on a backbone of $\alpha(1 \rightarrow 5)$-linked sugars with a number of $\alpha(1 \rightarrow 3)$-linked residues forming 3,5-Araf branchpoints (Daffé et al. 1990). Further $\alpha(1$ $\rightarrow$ 5)-linked Araf sugars are attached subsequent to this branchpoint with the nonreducing ends terminated by $\beta(1 \rightarrow 2)$ Araf residues. The final structural motif (Araf- $\beta(1 \rightarrow 2)$-Araf- $\alpha(1-)_{2}$ 
L.J. Alderwick et al.

$\rightarrow 3,5$-Araf- $\alpha(1 \rightarrow 5)$-Araf- $\alpha(1 \rightarrow))$ is a distinctive hexa-arabinoside $\left(\right.$ Ara $\left._{6}\right)$ of which approximately two-thirds are esterified with mycolic acids (McNeil et al. 1991). AG from $M$. tuberculosis is also further decorated with succinyl residues and galactosamine (GalN) located on the 2-position of an inner 3,5- $\alpha$-D-Araf bifurcation point of approximately one-third of the arabinan tricosamers (Draper et al. 1997; Lee et al. 2006; Bhamidi et al. 2008; Peng et al. 2012). The last two decades has witnessed a dramatic increase in our understanding of how this complex polymer is assembled. Much emphasis has been placed on investigating the molecular genetics of how this complex structure is assembled in mycobacteria. The complete sequencing of several genomes from mycobacteria and other closely related species has provided major impetus in the identification and the study of the enzymes involved in the biosynthesis of this exceptional structure, with the hope of uncovering new drug targets.

\section{Biosynthesis of Arabinogalactan \\ Biosynthesis of the Linker Unit}

The crucial structural role of the LU in the attachment of AG to PG, as well as the presence of L-rhamnose, a sugar absent in humans, makes the biosynthetic pathway leading to the formation of this disaccharide an attractive drug target (Ma et al. 2001). In M. tuberculosis, LU biosynthesis is initiated on the isoprenoid lipid carrier decaprenyl-phosphate $\left(\mathrm{C}_{50}-\mathrm{P}\right)$, whereby GlcNAc-phosphate is transferred from the activated sugar donor UDP-GlcNAc, thus forming $\mathrm{C}_{50}$-P-P-GlcNAc, referred to as glycolipid 1 (GL-1) (Mikusova et al. 1996). Rv1302 shows a high degree of homology with the WecA protein from E. coli (Amer and Valvano 2002; Lehrer et al.2007). Recent biochemical characterization of this enzyme shows that Rv1302 is indeed a decaprenyl-phosphate $\alpha-N$-acetylglucosaminyltransferase responsible for the formation of GL-1 (Ishizaki et al. 2013), and the gene encoding WecA is essential for growth in M. smegmatis (Jin et al. 2010). The LU is completed by the subsequent action of the rhamnosyltransferase
WbbL, which adds an L-Rhap to the 3-position of the GlcNAc of GL-1, this forming glycolipid 2 (GL-2) (Mills et al. 2004). WbbL uses the highenergy nucleotide sugar donor dTDP-rhamnose as a substrate for the formation of GL-2. Because formation of GL-2 is an essential biosynthetic step (Mills et al. 2004), the biosynthetic pathway leading to the formation dTDP-rhamnose has been heavily investigated, and a number of inhibitors of this process have been reported (Ma et al. 2001, 2002; Babaoglu et al. 2003; Kantardjieff et al. 2004). Synthesis of dTDP-Rha occurs via a linear 4-stage pathway using the gene products of rmlABCD. RmlA (Rv0334) sets in motion the sequence of reactions, converting dTTP $+\alpha$-D-glucose 1-phosphate to dTDP-glucose $+\mathrm{PP}_{\mathrm{i}}$ (Ma et al. 1997). The enzyme was cloned from M. tuberculosis and transformed into an E. coli strain devoid of four dTDP-Rha biosynthetic genes. Cellular extract analysis revealed an abundance of $\alpha$-D-Glc-P thymidylyltransferase activity confirming its proposed function (Ma et al. 1997). The product of RmlA activity is then shuttled through three sequential reactions catalyzed by dTDP-D-glucose 4,6-dehydratase (Rv3464, RmlB), dTDP-4-keto-6-deoxy-D-glucose 3,5 epimerase (Rv3465, RmlC) and dTDPRha synthase (Rv3266, RmlD) (Hoang et al. 1999; Stern et al. 1999; Ma et al. 2001). Both $\mathrm{rmlB}$ and $\mathrm{rmlC}$ genes have also been shown as being essential for mycobacterial growth ( $\mathrm{Li}$ et al. 2006).

\section{Galactan Precursor Synthesis}

The Gal $f$ residues of the galactan domain are incorporated from the high-energy sugar nucleotide donor UDP-Galf, which is formed via two reactions. In E. coli, galactosyl residues in the pyranose ring form (UDP-Galp) are synthesized by the action of GalE, a UDP-glucose 4-epimerase, which uses UDP-glucopyranose (UDP-Glcp) as its substrate (Lemaire and Muller-Hill 1986). A study using cell-free extracts of $M$. smegmatis and radiolabeled UDP-Galp showed the presence of UDP-glucose 4-epimerase activity, and the amino-terminal sequence of the isolated protein was shown to be similar to that of M. tuberculosis Rv3634 (Weston et al. 
1997). Conversion of UDP-Galp to the furanose form occurs via ring contraction catalyzed by the flavoenzyme UDP-galactopyranose mutase (Glf) that was first recognized in E. coli (Nassau et al. 1996) and subsequently in M. smegmatis and M. tuberculosis (Rv3809c) (Weston et al. 1997). Allelic exchange experiments of glf in M. smegmatis highlighted the essentiality of this gene (Pan et al. 2001).

\section{Arabinan Precursor Synthesis}

As we shall see in the following section, mycobacterial D-arabinan assembly follows a linear biosynthetic pathway that involves an assortment of membrane-bound glycosyltransferases. Although D-arabinan contains a complex mixture of glycosidic linkages, decaprenylphosphoryl- $\beta$-D-arabinofuranose (DPA) is used exclusively by all of the enzymes involved in this pathway as a lipid-linked, activated Araf substrate (Wolucka et al. 1994; Xin et al. 1997; Alderwick et al. 2005). Synthetically derived $\mathrm{DP}\left[{ }^{14} \mathrm{C}\right] \mathrm{A}$ and an array of synthetic acceptors have determined that DPA provides Araf units in the in vitro formation of 2-linked, 3-linked, and 5-linked arabinofuranosyl linkages present in the arabinans of AG and LAM (Belanger et al. 1996; Lee et al. 1997; Xin et al. 1997).

Because DPA is such an indispensable molecule required for mycobacterial cell wall biosynthesis, the elucidation of the biosynthetic pathway leading to its formation has received much attention. Classical biosynthesis of such polyprenylphosphate sugars chiefly involves the donation of a glycosyl residue from an activated sugar nucleotide donor to a polyprenylphosphate substrate. Interestingly sugar nucleotides of arabinose (UDP-Ara or GDP-Ara) have not been identified in mycobacteria. Instead, the carbon skeleton of the arabinosyl residues are derived from 5-phosphoribosyl-1-pyrophosphate ( $p R p p)$, a metabolite that emerges from the nonoxidative pentose shunt pathway (Scherman et al. 1995). M. tuberculosis has a single pRpp synthetase, which is responsible for the formation of $\mathrm{pRpp}$ and uses both ribose 5-phosphate and ATP as its substrates (Alderwick et al. 2011). The 5-phospho- $\alpha$-D-ribose-1-pyro- phosphate:decaprenyl phosphate 5-phosphoribosyl transferase (Rv3806c), also annotated as UbiA, transfers the ribose-5-phosphate moiety from $\mathrm{pRpp}$ to decaprenylphosphate, ultimately forming decaprenylphosphoryl-5- $\beta$-D-phosphoribofuranose (DPPR) (Huang et al. 2005, 2008). The essentiality of UbiA was highlighted in a study that used Corynebacterium glutamicum as a model organism to investigate the molecular genetics of mycobacterial D-arabinan biosynthesis. A ubiA-deficient strain of C. glutamicum resulted in a cell wall phenotype that was completely devoid of arabinose, giving incontrovertible evidence that DPA is indeed the only Araf donor for D-arabinan biosynthesis (Alderwick et al. 2005, 2006a). DPPR is dephosphorylated to decaprenylphosphoryl- $\beta$-D-ribofuranose (DPR) by a phosphatase enzyme encoded by Rv3807c. Genetic deletion and subsequent phenotypic studies of the M. smegmatis homolog (MSMEG6402) suggest that although this gene is not essential, its enzymatic function is required to enable cell wall biosynthesis to continue unabated (Jiang et al. 2011). At this point, DPR is epimerized to DPA in a two-step epimerization process that involves two enzymes, DprE1 and DprE2. DprE1, encoded by $r v 3790$, is an oxidoreductase that serves to oxidize the C-2 hydroxyl of the ribose moiety of DPR to form decaprenylphosphoryl-2-keto- $\beta$ D-erythro-pentofuranose (DPK), which is an intermediate metabolite of this essential pathway (Mikusova et al. 2005). DprE2, encoded by rv3791, then reduces the C2-keto of DPK, resulting in the complete synthesis of the sole Araf donor, DPA (Mikusova et al. 2005).

At this point, it is worth giving special attention to DprE1, primarily because several recent chemical biology studies have shown that this enzyme is particularly susceptible to inhibition by a variety of small-molecule inhibitors that also show potent antimycobacterial activity. Benzothiazinones (BTZs) are a new class of sulfur-containing heterocyclic compounds that kill $M$. tuberculosis with nanomolar potency by targeting DprE1 (Makarov et al. 2009). Several biochemical and structural biology studies have shown that BTZs are suicide inhibitors, whereby BTZ is activated by DprE1, a FAD-de- 
L.J. Alderwick et al.

pendent enzyme, forming a covalent semimercaptal bond with a key active-site cystine residue (Trefzer et al. 2010, 2012; Batt et al. 2012). Subsequent high-throughput screening and highcontent screening experiments have revealed that DprE1 is an extremely "druggable" enzyme, with molecules such as the dinitrobenzamides (DNBs), nitrotriazoles, pyrazolopyridones, azaindoles, and a benzothiazoles (TCA1) (Christophe et al. 2009; Stanley et al. 2012; Shirude et al. 2013; Wang et al. 2013; Panda et al. 2014).

Because of the apparent vulnerability of DprE1 as a key enzyme in cell wall biosynthesis, it has been lauded by many within the mycobacterial research community as a "magic drug target." Targeting D-arabinan biosynthesis ultimately results in the removal of covalent linkage between peptidoglycan and the outer mycolate layers and is a salutary approach to the development of new antimycobacterial agents. However, this is insufficient evidence to explain the vulnerable nature of DprE1 as a "magic drug target." A recent investigation into the vulnerability of DprE1 as a drug target showed that the primary consequence of DprE1 inhibition is not simply the loss of DPA formation, rather it is the accumulation of DPR in the cytoplasmic membrane that induces synthetic lethality, depleting the TB bacilli of the limited supply of decaprenylphosphate that is required for both AG and PG biosynthesis to proceed unhindered (Grover et al. 2014). As we shall see, a variety of membrane-bound arabinofuranosyltransferases are required to assemble D-arabinan on the periplasmic face of the cytoplasmic membrane. Because DPA is synthesized on the inner leaflet of the cytoplasmic membrane, it is necessary for DPA to be translocated to position this Araf donor in the correct orientation. Rv3789 has been identified as a DPA flippase responsible for this activity (Larrouy-Maumus et al. 2012).

\section{Galactan Biosynthesis}

The assortment of glycosyl linkages within the galactan moiety leads to the supposition that at least two Gal $f$ transferases (GalTs) are required for its complete biosynthesis. GlfT1 (Rv3782) is classified as an inverting glycosyltransferase-2 (GT-2) of the GT-A superfamily, and it is recognized as the GalT responsible for the initial transfer of two Galf residues, using UDP-Galf as a substrate, to form both $\mathrm{C}_{50}$-P-P-GlcNAcRha-Galf (GL-3) and $\mathrm{C}_{50}$-P-P-GlcNAc-RhaGalf-Galf (GL-4) (Mikusova et al. 2006; Alderwick et al. 2008). Using a novel neoglycolipid acceptor assay that contained isolated E. coli membranes expressing GlfT2 (Rv3808c), it was shown that this enzyme has dual functionality, acting both as a UDP-Galf: $\beta-D-(1 \rightarrow 5)$ GalT and UDP-Galf: $\beta$-D- $(1 \rightarrow 6)$ GalT, responsible for the polymerization of approximately 30 Galf residues with alternating $\beta(1 \rightarrow 5)$ and $\beta(1 \rightarrow 6)$ linkages (Kremer et al. 2001; Mikusova et al. 2006). Apart from being a bifunctional GalT, GlfT2 displays additional interesting features: By using a substrate tethering mechanism, it is able to have intrinsic control of the chain length of the galactan product (May et al. 2009). Further structural analysis of GlfT2 using X-ray crystallography and NMR has shed further light on how this unique enzyme is tetrameric and is able to control chain length processivity and bifunctionality using a single active site (Szczepina et al. 2009; Wheatley et al. 2012).

\section{Arabinan Biosynthesis}

A Brief Digression on Ethambutol. As discussed earlier, D-arabinan is a pivotal scaffold structure, which serves to covalently connect PG to the outer mycolic acid layer. Its biosynthesis is also targeted by the frontline drug ethambutol (EMB). EMB is a synthetic compound that was first recognized as an antimycobacterial agent in 1961 (Thomas et al. 1961). Early work by Kilburn and Greenberg observed an unanticipated increase in viable cells during the initial $4 \mathrm{~h}$ after addition of EMB to M. smegmatis cultures (Kilburn and Takayama 1981). It was postulated that large bacillary clusters disaggregated because of a possible reduction in lipid content, which would lead to the apparent increase in colony-forming units (CFUs) (Kilburn and Takayama 1981). This theory was supported by Takayama and coworkers who conducted a series of early studies into the effects 
of the EMB on M. smegmatis, reporting that inhibition of mycolic acid transfer into the cell wall and the simultaneous accumulation of trehalose-monomycolate (TMM), trehalose-dimycolate (TDM), and free mycolic acids occurred within 15 min of drug administration, suggesting that the target may be a mycolytransferase responsible for the transfer of mycolic acids onto the arabinan polymer (Takayama et al. 1979; Kilburn and Takayama 1981). However, it was later discovered, from observing the incorporation of $\left[{ }^{14} \mathrm{C}\right]$ glucose into the cell wall D-arabinose monomers, that EMB inhibits the formation of D-arabinan (Takayama and Kilburn 1989), whereas synthesis of D-galactan of AG remained unaffected (Mikusova et al. 1995). A major breakthrough in the discovery of the precise EMB cellular target arose through exploitation of a moderately resistant strain from the related Mycobacterium avium species. A genomic library from the aforementioned strain was screened and overexpressed in an otherwise susceptible $M$. smegmatis host, leading to the identification of a resistance-conferring region encompassing three complete open reading frames (ORFs), embR, embA, and $e m b B$ (Belanger et al. 1996). Moreover, use of an EMB-sensitive cell-free arabinan biosynthetic assay showed that arabinosyltransferase activity was restored with $e m b A B$ overexpression. Interestingly, neither $e m b A$ or $e m b B$ alone was sufficient to confer multicopy resistance, thus supporting the supposition that they are translationally coupled, possibly forming a multienzyme complex (Belanger et al. 1996). EMB resistance was also used to identify the embCAB gene cluster from M. smegmatis, which was subsequently characterized in $M$. $t u$ berculosis and M. leprae, all of which possess the same syntenic organization and encode homologs of the $e m b A$ and $e m b B$ genes from $M$. avium (Lety et al. 1997; Telenti et al. 1997). Escuyer et al. (2001) created individual genetic knockouts in M. smegmatis, embC, embA, and $e m b B$, all of which were viable, with the most profound effects observed in the $e m b B$ mutant. Individual inactivation of $e m b A$ and $e m b B$ resulted in the diminished incorporation of arabinose into AG, specifically, the terminal dis- accharide $\beta$-D-Araf $-(1 \rightarrow 2)-\alpha$-D-Araf, normally situated on the $3-\mathrm{OH}$ of the 3,5-linked Araf residue.

\section{Identification of Novel Arabinofuranosyltransferases and the Use of C. glutamicum and M. smegmatis as Model Organisms}

The Emb proteins, although novel, possess membrane topologies consistent with other glycosyltransferases (GTs) that use lipid-linked precursors, and do not resemble the more typical nucleotide-diphosphate (NDP) sugar donor requiring GTs. To date, the carbohydrate-active enzymes (CAZy) database has classified GTs into approximately 95 families with three large structural superfamilies, GT-A, GT-B, and GT-C (Liu and Mushegian 2003). GT-A and GT-B enzymes use NDP-sugar donors and are either globular or peripheral membrane proteins. The GT-C superfamily are large integral membrane proteins, all of which contain eight to 13 predicted transmembrane (TM) domains, with typically low sequence similarity but a conserved amino acid motif, called the DxD motif, generally positioned in the first or second predicted extracytoplasmic loop, and is thought to be required for binding the polyprenylphosphosugar substrate (Berg et al. 2007). The Emb proteins have been classified as GT-Cs, comprising approximately 1100 amino acids and 12-13 TM-spanning regions (Berg et al. 2005; Seidel et al. 2007b). Efforts to generate viable $e m b A / e m b B$ mutants in $M$. tuberculosis and an embAB double mutant in M. smegmatis have so far proven unfruitful, highlighting their essentiality in mycobacteria. The Corynebacterianeae taxon encompasses Mycobacterium species as well as Corynebacterium species, such as Corynebacterium diphtheriae and C. glutamicum. Corynebacterium are deemed the archetype of Corynebacterianeae, and because they maintain a low frequency of gene duplications and modifications, they also possess a cell wall core remarkably similar to $M$. tuberculosis and have served as a useful tool and model organism to study otherwise essential orthologous M. tuberculosis genes. Alderwick et al. 
L.J. Alderwick et al.

(2005) successfully constructed a C. glutamicum mutant with its singular emb gene disrupted $(\mathrm{Cg}-\mathrm{emb})$, and subsequent phenotypic analyses of this mutant revealed an almost total loss of cell wall arabinan, except for terminal $t$-Arafresidues decorating the galactan backbone. Moreover, EMB treatment of wild-type C. glutamicum produced a profile identical to that of the mutant, illustrating that $\mathrm{Cg}$-emb is indeed the target of EMB and furthermore that another AraT responsible for "priming" the galactan backbone must exist. As described earlier, disruption of the 5-phospho- $\alpha$-D-ribose-1-pyrophosphate: decaprenyl phosphate 5-phosphoribosyl transferase ortholog $(\mathrm{Cg}-u b i \mathrm{~A})$, resulted in total ablation of Araf residues, indicating that the unidentified AraTwas also DPA-dependent (Alderwick et al. 2005). This pioneering study paved the way for the discovery of several novel GT-C arabinofuransyltransferases, each of which plays key roles in D-arabinan biosynthesis. AftA was identified as the enzyme responsible for priming the 8 th, 10th, and 12th Galf residues of the galactan backbone, which are elongated by the Emb proteins in an $\alpha(1 \rightarrow 5)$-linked fashion (Alderwick et al. 2006b). The M. smegmatis AftA homolog (MSMEG_6386) could only be chromosomally deleted in a merodiploid strain, highlighting its essentiality in mycobacteria (Shi et al. 2008). Both C. glutamicum and $M$. smegmatis model systems were used in combination to identify AftC as the enzyme responsible for introducing $\alpha(1 \rightarrow 3)$ Araf linkages into Darabinan of AG and lipoarabinomannan (LAM) (Birch et al. 2008, 2010). Standing at 1400 amino acids in length and with a molecular mass of $\sim 150 \mathrm{kDa}, \mathrm{AftD}$ represents the largest of the GT-C AraTs present in M. tuberculosis. It has been shown that AftD shows $\alpha(1 \rightarrow 3)$ Araf transferase activity, but because of its disproportionally large size, is speculated to have additional functions, such as being a scaffold protein for the recruitment of additional cell wall biosynthetic enzymes (Skovierova et al. 2009). Again, C. glutamicum was used to identify AftB as the enzyme that transfers terminal $\beta(1 \rightarrow 2)$ Araf residues into the nonreducing $\mathrm{Ara}_{6}$ motif of AG, thus bringing AG biosynthesis to a halt (Seidel et al. 2007a).

\section{REFERENCES}

Adam A, Petit JF, Wietzerbin-Falszpan J, Sinay P, Thomas DW, Lederer E. 1969. L'acide N-glycolylmuramique, constituant des parois de Mycobacterium smegmatis: Identification par spectrometrie de masse. FEBS Lett 4: 87-92.

Alderwick LJ, Radmacher E, Seidel M, Gande R, Hitchen PG, Morris HR, Dell A, Sahm H, Eggeling L, Besra GS. 2005. Deletion of Cg-emb in Corynebacterianeae leads to a novel truncated cell wall arabinogalactan, whereas inactivation of Cg-ubiA results in an arabinan-deficient mutant with a cell wall galactan core. J Biol Chem 280: 32362-32371.

Alderwick LJ, Dover LG, Seidel M, Gande R, Sahm H, Eggeling L, Besra GS. 2006a. Arabinan-deficient mutants of Corynebacterium glutamicum and the consequent flux in decaprenylmonophosphoryl-D-arabinose metabolism. Glycobiology 16: 1073-1081.

Alderwick LJ, Seidel M, Sahm H, Besra GS, Eggeling L. 2006b. Identification of a novel arabinofuranosyltransferase (AftA) involved in cell wall arabinan biosynthesis in Mycobacterium tuberculosis. J Biol Chem 281: 15653 15661.

Alderwick LJ, Dover LG, Veerapen N, Gurcha SS, Kremer L, Roper DL, Pathak AK, Reynolds RC, Besra GS. 2008. Expression, purification and characterisation of soluble GlfT and the identification of a novel galactofuranosyltransferase Rv3782 involved in priming GlfT-mediated galactan polymerisation in Mycobacterium tuberculosis. Protein Expr Purif 58: 332-341.

Alderwick LJ, Lloyd GS, Lloyd AJ, Lovering AL, Eggeling L, Besra GS. 2011. Biochemical characterization of the Mycobacterium tuberculosis phosphoribosyl-1-pyrophosphate synthetase. Glycobiology 21: 410-425.

Amar C, Vilkas E. 1973. [Isolation of arabinose phosphate from the walls of Mycobacterium tuberculosis $\mathrm{H} 37 \mathrm{Ra}$ ]. C R Acad Sci Hebd Seances Acad Sci D 277: 1949-1951.

Amer AO, Valvano MA. 2002. Conserved aspartic acids are essential for the enzymic activity of the WecA protein initiating the biosynthesis of $O$-specific lipopolysaccharide and enterobacterial common antigen in Escherichia coli. Microbiology 148: 571-582.

Anthony KG, Strych U, Yeung KR, Shoen CS, Perez O, Krause KL, Cynamon MH, Aristoff PA, Koski RA. 2011. New classes of alanine racemase inhibitors identified by high-throughput screening show antimicrobial activity against Mycobacterium tuberculosis. PLoS ONE 6: e20374.

Azuma I, Kimura H, Niinaka T, Aoki T, Yamamura Y. 1968. Chemical and immunological studies on mycobacterial polysaccharides. 1. Purification and properties of polysaccharides from human tubercle bacilli. J Bacteriol 95: 263-271.

Babaoglu K, Page MA, Jones VC, McNeil MR, Dong C, Naismith JH, Lee RE. 2003. Novel inhibitors of an emerging target in Mycobacterium tuberculosis; substituted thiazolidinones as inhibitors of dTDP-rhamnose synthesis. Bioorg Med Chem Lett 13: 3227-3230.

Barreteau H, Kovac A, Boniface A, Sova M, Gobec S, Blanot D. 2008. Cytoplasmic steps of peptidoglycan biosynthesis. FEMS Microbiol Rev 32: 168-207.

Basavannacharya C, Moody PR, Munshi T, Cronin N, Keep NH, Bhakta S. 2010a. Essential residues for the enzyme 
activity of ATP-dependent MurE ligase from Mycobacterium tuberculosis. Protein Cell 1: 1011-1022.

Basavannacharya C, Robertson G, Munshi T, Keep NH, Bhakta S. 2010b. ATP-dependent MurE ligase in Mycobacterium tuberculosis: Biochemical and structural characterisation. Tuberculosis (Edinb) 90: 16-24.

Batt SM, Jabeen T, Bhowruth V, Quill L, Lund PA, Eggeling L, Alderwick LJ, Futterer K, Besra GS. 2012. Structural basis of inhibition of Mycobacterium tuberculosis DprE1 by benzothiazinone inhibitors. Proc Natl Acad Sci 109: 11354-11359.

Belanger AE, Besra GS, Ford ME, Mikusova K, Belisle JT, Brennan PJ, Inamine JM. 1996. The embAB genes of Mycobacterium avium encode an arabinosyl transferase involved in cell wall arabinan biosynthesis that is the target for the antimycobacterial drug ethambutol. Proc Natl Acad Sci 93: 11919-11924.

Berg S, Starbuck J, Torrelles JB, Vissa VD, Crick DC, Chatterjee D, Brennan PJ. 2005. Roles of conserved proline and glycosyltransferase motifs of EmbC in biosynthesis of lipoarabinomannan. J Biol Chem 280: 5651-5663.

Berg S, Kaur D, Jackson M, Brennan PJ. 2007. The glycosyltransferases of Mycobacterium tuberculosis-Roles in the synthesis of arabinogalactan, lipoarabinomannan, and other glycoconjugates. Glycobiology 17: 35-56R.

Besra GS, Khoo KH, McNeil MR, Dell A, Morris HR, Brennan PJ. 1995. A new interpretation of the structure of the mycolyl-arabinogalactan complex of Mycobacterium tuberculosis as revealed through characterization of oligoglycosylalditol fragments by fast-atom bombardment mass spectrometry and $1 \mathrm{H}$ nuclear magnetic resonance spectroscopy. Biochemistry 34: 4257-4266.

Bhamidi S, Scherman MS, Rithner CD, Prenni JE, Chatterjee D, Khoo KH, McNeil MR. 2008. The identification and location of succinyl residues and the characterization of the interior arabinan region allow for a model of the complete primary structure of Mycobacterium tuberculosis mycolyl arabinogalactan. J Biol Chem 283: $12992-$ 13000.

Birch HL, Alderwick LJ, Bhatt A, Rittmann D, Krumbach K, Singh A, Bai Y, Lowary TL, Eggeling L, Besra GS. 2008. Biosynthesis of mycobacterial arabinogalactan: Identification of a novel $\alpha(1 \rightarrow 3)$ arabinofuranosyltransferase. Mol Microbiol 69: 1191-1206.

Birch HL, Alderwick LJ, Appelmelk BJ, Maaskant J, Bhatt A, Singh A, Nigou J, Eggeling L, Geurtsen J, Besra GS. 2010. A truncated lipoglycan from mycobacteria with altered immunological properties. Proc Natl Acad Sci 107: 2634 2639.

Bouhss A, Dementin S, van Heijenoort J, Parquet C, Blanot D. 1999. Formation of adenosine $5^{\prime}$-tetraphosphate from the acyl phosphate intermediate: A difference between the MurC and MurD synthetases of Escherichia coli. FEBS Lett 453: 15-19.

Brennan PJ, Nikaido H. 1995. The envelope of mycobacteria. Annu Rev Biochem 64: 29-63.

Butler EK, Davis RM, Bari V, Nicholson PA, Ruiz N. 2013. Structure-function analysis of MurJ reveals a solvent-exposed cavity containing residues essential for peptidoglycan biogenesis in Escherichia coli. J Bacteriol 195: 46394649 .
Calvanese L, Falcigno L, Maglione C, Marasco D, Ruggiero A, Squeglia F, Berisio R, D'Auria G. 2014. Structural and binding properties of the PASTA domain of PonA2, a key penicillin binding protein from Mycobacterium tuberculosis. Biopolymers 101: 712-719.

Chatterjee D, Bozic CM, McNeil M, Brennan PJ. 1991. Structural features of the arabinan component of the lipoarabinomannan of Mycobacterium tuberculosis. J Biol Chem 266: 9652-9660.

Chen KT, Kuan YC, Fu WC, Liang PH, Cheng TJ, Wong CH, Cheng WC. 2013. Rapid preparation of mycobacterium $\mathrm{N}$-glycolyl Lipid I and Lipid II derivatives: A biocatalytic approach. Chemistry 19: 834-838.

Christophe T, Jackson M, Jeon HK, Fenistein D, ContrerasDominguez M, Kim J, Genovesio A, Carralot JP, Ewann F, Kim EH, et al. 2009. High content screening identifies decaprenyl-phosphoribose $2^{\prime}$ epimerase as a target for intracellular antimycobacterial inhibitors. PLoS Pathog 5: e1000645.

Correale S, Ruggiero A, Capparelli R, Pedone E, Berisio R. 2013. Structures of free and inhibited forms of the L,Dtranspeptidase LdtMt1 from Mycobacterium tuberculosis. Acta Crystallogr D Biol Crystallogr 69: 1697-1706.

Daffé M, Brennan PJ, McNeil M. 1990. Predominant structural features of the cell wall arabinogalactan of Mycobacterium tuberculosis as revealed through characterization of oligoglycosyl alditol fragments by gas chromatography/mass spectrometry and by ${ }^{1} \mathrm{H}$ and ${ }^{13} \mathrm{C}$ NMR analyses. J Biol Chem 265: 6734-6743.

Dasgupta A, Datta P, Kundu M, Basu J. 2006. The serine/ threonine kinase PknB of Mycobacterium tuberculosis phosphorylates $\mathrm{PBPA}$, a penicillin-binding protein required for cell division. Microbiology 152: 493-504.

De Smet KA, Kempsell KE, Gallagher A, Duncan K, Young DB. 1999. Alteration of a single amino acid residue reverses fosfomycin resistance of recombinant MurA from Mycobacterium tuberculosis. Microbiology 145: $3177-$ 3184.

Dmitriev BA, Ehlers S, Rietschel ET, Brennan PJ. 2000. Molecular mechanics of the mycobacterial cell wall: From horizontal layers to vertical scaffolds. Int J Med Microbiol 290: $251-258$.

Dmitriev BA, Toukach FV, Schaper KJ, Holst O, Rietschel ET, Ehlers S. 2003. Tertiary structure of bacterial murein: The scaffold model. J Bacteriol 185: 3458-3468.

Draper P, Khoo KH, Chatterjee D, Dell A, Morris HR. 1997. Galactosamine in walls of slow-growing mycobacteria. Biochem J 327: 519-525.

Durand P, Golinelli-Pimpaneau B, Mouilleron S, Badet B, Badet-Denisot MA. 2008. Highlights of glucosamine-6P synthase catalysis. Arch Biochem Biophys 474: 302-317.

Escuyer VE, Lety MA, Torrelles JB, Khoo KH, Tang JB, Rithner CD, Frehel C, McNeil MR, Brennan PJ, Chatterjee D. 2001. The role of the $e m b A$ and $e m b B$ gene products in the biosynthesis of the terminal hexaarabinofuranosyl motif of Mycobacterium smegmatis arabinogalactan. J Biol Chem 276: 48854-48862.

Essers L, Schoop HJ. 1978. Evidence for the incorporation of molecular oxygen, a pathway in biosynthesis of Nglycolylmuramic acid in Mycobacterium phlei. Biochim Biophys Acta 544: 180-184. 


\section{L.J. Alderwick et al.}

Falk PJ, Ervin KM, Volk KS, Ho HT. 1996. Biochemical evidence for the formation of a covalent acyl-phosphate linkage between UDP- $N$-acetylmuramate and ATP in the Escherichia coli UDP- $N$-acetylmuramate:L-alanine ligasecatalyzed reaction. Biochemistry 35: 1417-1422.

Feng Z, Barletta RG. 2003. Roles of Mycobacterium smegmatis D-alanine:D-alanine ligase and D-alanine racemase in the mechanisms of action of and resistance to the peptidoglycan inhibitor D-cycloserine. Antimicrob Agents Chemother 47: 283-291.

Gateau O, Bordet C, Michel G. 1976. [Study of the formation of $\mathrm{N}$-glycolylmuramic acid from Nocardia asteroides (author's transl)]. Biochim Biophys Acta 421: 395-405.

Ghuysen JM. 1968. Use of bacteriolytic enzymes in determination of wall structure and their role in cell metabolism. Bacteriol Rev 32: 425-464.

Grover S, Alderwick LJ, Mishra AK, Krumbach K, Marienhagen J, Eggeling L, Bhatt A, Besra GS. 2014. Benzothiazinones mediate killing of Corynebacterineae by blocking decaprenyl phosphate recycling involved in cell wall biosynthesis. J Biol Chem 289: 6177-6187.

Gupta R, Lavollay M, Mainardi JL, Arthur M, Bishai WR, Lamichhane G. 2010. The Mycobacterium tuberculosis protein LdtMt2 is a nonclassical transpeptidase required for virulence and resistance to amoxicillin. Nat Med 16: $466-469$.

Hett EC, Chao MC, Rubin EJ. 2010. Interaction and modulation of two antagonistic cell wall enzymes of mycobacteria. PLoS Pathog 6: e1001020.

Hoang TT, Ma Y, Stern RJ, McNeil MR, Schweizer HP. 1999. Construction and use of low-copy number T7 expression vectors for purification of problem proteins: Purification of Mycobacterium tuberculosis RmlD and pseudomonas aeruginosa LasI and RhlI proteins, and functional analysis of purified RhlI. Gene 237: 361-371.

Huang H, Scherman MS, D’Haeze W, Vereecke D, Holsters M, Crick DC, McNeil MR. 2005. Identification and active expression of the Mycobacterium tuberculosis gene encoding 5-phospho- $\{\alpha\}$-D-ribose-1-diphosphate: decaprenyl-phosphate 5-phosphoribosyltransferase, the first enzyme committed to decaprenylphosphoryl-darabinose synthesis. J Biol Chem 280: 24539-24543.

Huang H, Berg S, Spencer JS, Vereecke D, D’Haeze W, Holsters M, McNeil MR. 2008. Identification of amino acids and domains required for catalytic activity of DPPR synthase, a cell wall biosynthetic enzyme of Mycobacterium tuberculosis. Microbiology 154: 736-743.

Ishizaki Y, Hayashi C, Inoue K, Igarashi M, Takahashi Y, Pujari V, Crick DC, Brennan PJ, Nomoto A. 2013. Inhibition of the first step in synthesis of the mycobacterial cell wall core, catalyzed by the GlcNAc-1-phosphate transferase WecA, by the novel caprazamycin derivative CPZEN-45. J Biol Chem 288: 30309-30319.

Jagtap PK, Soni V, Vithani N, Jhingan GD, Bais VS, Nandicoori VK, Prakash B. 2012. Substrate-bound crystal structures reveal features unique to Mycobacterium tuberculosis $\mathrm{N}$-acetyl-glucosamine 1-phosphate uridyltransferase and a catalytic mechanism for acetyl transfer. $J$ Biol Chem 287: 39524-39537.

Jagtap PK, Verma SK, Vithani N, Bais VS, Prakash B. 2013. Crystal structures identify an atypical two-metal-ion mechanism for uridyltransfer in GlmU: Its significance to sugar nucleotidyl transferases. J Mol Biol 425: $1745-$ 1759 .

Jha RK, Katagihallimath N, Hota SK, Das KS, de Sousa SM. 2012. An assay for exogenous sources of purified MurG, enabled by the complementation of Escherichia coli murG(Ts) by the Mycobacterium tuberculosis homologue. FEMS Microbiol Lett 326: 161-167.

Jiang T, He L, Zhan Y, Zang S, Ma Y, Zhao X, Zhang C, Xin Y. 2011. The effect of MSMEG_6402 gene disruption on the cell wall structure of Mycobacterium smegmatis. Microb Pathog 51: 156-160.

Jin Y, Xin Y, Zhang W, Ma Y. 2010. Mycobacterium tuberculosis Rv1302 and Mycobacterium smegmatis MSMEG_4947 have WecA function and MSMEG_4947 is required for the growth of M. smegmatis. FEMS Microbiol Lett 310: 54-61.

Kanetsuna F. 1968. Chemical analyses of mycobacterial cell walls. Biochim Biophys Acta 158: 130-143.

Kanetsuna F, Imaeda T, Cunto G. 1969. On the linkage between mycolic acid and arabinogalactan in phenoltreated myobacterial cell walls. Biochim Biophys Acto 173: $341-344$.

Kantardjieff KA, Kim CY, Naranjo C, Waldo GS, Lekin T, Segelke BW, Zemla A, Park MS, Terwilliger TC, Rupp B. 2004. Mycobacterium tuberculosis RmlC epimerase (Rv3465): A promising drug-target structure in the rhamnose pathway. Acta Crystallogr D Biol Crystallogr 60: $895-902$.

Kilburn JO, Takayama K. 1981. Effects of ethambutol on accumulation and secretion of trehalose mycolates and free mycolic acid in Mycobacterium smegmatis. Antimicrob Agents Chemother 20: 401-404.

Kim DH, Lees WJ, Kempsell KE, Lane WS, Duncan K, Walsh CT. 1996. Characterization of a Cys115 to Asp substitution in the Escherichia coli cell wall biosynthetic enzyme UDP-GlcNAc enolpyruvyl transferase (MurA) that confers resistance to inactivation by the antibiotic fosfomycin. Biochemistry 35: 4923-4928.

Kim HS, Kim J, Im HN, Yoon JY, An DR, Yoon HJ, Kim JY, Min HK, Kim SJ, Lee JY, et al. 2013. Structural basis for the inhibition of Mycobacterium tuberculosis L,D-transpeptidase by meropenem, a drug effective against extensively drug-resistant strains. Acta Crystallogr D Biol Crystallogr 69: 420-431.

Kremer L, Dover LG, Morehouse C, Hitchin P, Everett M, Morris HR, Dell A, Brennan PJ, McNeil MR, Flaherty C, et al. 2001. Galactan biosynthesis in Mycobacterium tuberculosis. Identification of a bifunctional UDP-galactofuranosyltransferase. J Biol Chem 276: 26430-26440.

Kumar V, Saravanan P, Arvind A, Mohan CG. 2011. Identification of hotspot regions of MurB oxidoreductase enzyme using homology modeling, molecular dynamics and molecular docking techniques. J Mol Model 17: 939953.

Larrouy-Maumus G, Skovierova H, Dhouib R, Angala SK, Zuberogoitia S, Pham H, Villela AD, Mikusova K, Noguera A, Gilleron M, et al. 2012. A small multidrug resistance-like transporter involved in the arabinosylation of arabinogalactan and lipoarabinomannan in mycobacteria. J Biol Chem 287: 39933-39941.

Lederer E, Adam A, Ciorbaru R, Petit JF, Wietzerbin J. 1975. Cell walls of mycobacteria and related organisms; chem- 
istry and immunostimulant properties. Mol Cell Biochem 7: 87-104.

Lee RE, Brennan PJ, Besra GS. 1997. Mycobacterial arabinan biosynthesis: The use of synthetic arabinoside acceptors in the development of an arabinosyl transfer assay. Glycobiology 7: 1121-1128.

Lee A, Wu SW, Scherman MS, Torrelles JB, Chatterjee D, McNeil MR, Khoo KH. 2006. Sequencing of oligoarabinosyl units released from mycobacterial arabinogalactan by endogenous arabinanase: Identification of distinctive and novel structural motifs. Biochemistry 45: 1581715828.

Lee Y, Mootien S, Shoen C, Destefano M, Cirillo P, Asojo OA, Yeung KR, Ledizet M, Cynamon MH, Aristoff PA, et al. 2013. Inhibition of mycobacterial alanine racemase activity and growth by thiadiazolidinones. Biochem Pharmacol 86: 222-230.

Lehrer J, Vigeant KA, Tatar LD, Valvano MA. 2007. Functional characterization and membrane topology of Escherichia coli WecA, a sugar-phosphate transferase initiating the biosynthesis of enterobacterial common antigen and $\mathrm{O}$-antigen lipopolysaccharide. J Bacteriol 189: $2618-2628$.

Lemaire HG, Muller-Hill B. 1986. Nucleotide sequences of the gal E gene and the gal T gene of E. coli. Nucleic Acids Res 14: 7705-7711.

Lety MA, Nair S, Berche P, Escuyer V. 1997. A single point mutation in the embB gene is responsible for resistance to ethambutol in Mycobacterium smegmatis. Antimicrob Agents Chemother 41: 2629-2633.

Li W, Xin Y, McNeil MR, Ma Y. 2006. rmlB and rmlC genes are essential for growth of mycobacteria. Biochem Biophys Res Commun 342: 170-178.

Li Y, Zhou Y, Ma Y, Li X. 2011. Design and synthesis of novel cell wall inhibitors of Mycobacterium tuberculosis GlmM and GlmU. Carbohydr Res 346: 1714-1720.

Li S, Kang J, Yu W, Zhou Y, Zhang W, Xin Y, Ma Y. 2012. Identification of M. tuberculosis Rv3441c and M. smegmatis MSMEG_1556 and essentiality of M. smegmatis MSMEG_1556. PLoS ONE 7: e42769.

Li WJ, Li DF, Hu YL, Zhang XE, Bi LJ, Wang DC. 2013. Crystal structure of L,D-transpeptidase LdtMt2 in complex with meropenem reveals the mechanism of carbapenem against Mycobacterium tuberculosis. Cell Res 23: $728-731$.

Liu TY, Gotschlich EC. 1967. Muramic acid phosphate as a component of the mucopeptide of Gram-positive bacteria. J Biol Chem 242: 471-476.

Liu J, Mushegian A. 2003. Three monophyletic superfamilies account for the majority of the known glycosyltransferases. Protein Sci 12: 1418-1431.

Ma Y, Mills JA, Belisle JT, Vissa V, Howell M, Bowlin K, Scherman MS, McNeil M. 1997. Determination of the pathway for rhamnose biosynthesis in mycobacteria: Cloning, sequencing and expression of the Mycobacterium tuberculosis gene encoding $\alpha$-D-glucose-1-phosphate thymidylyltransferase. Microbiology 143: 937-945.

Ma Y, Stern RJ, Scherman MS, Vissa VD, Yan W, Jones VC, Zhang F, Franzblau SG, Lewis WH, McNeil MR. 2001. Drug targeting Mycobacterium tuberculosis cell wall synthesis: Genetics of dTDP-rhamnose synthetic enzymes and development of a microtiter plate-based screen for inhibitors of conversion of dTDP-glucose to dTDPrhamnose. Antimicrob Agents Chemother 45: 1407-1416.

Ma Y, Pan F, McNeil M. 2002. Formation of dTDP-rhamnose is essential for growth of mycobacteria. J Bacteriol 184: 3392-3395.

Mahapatra S, Crick DC, Brennan PJ. 2000. Comparison of the UDP- $N$-acetylmuramate:L-alanine ligase enzymes from Mycobacterium tuberculosis and Mycobacterium leprae. J Bacteriol 182: 6827-6830.

Mahapatra S, Scherman H, Brennan PJ, Crick DC. 2005. N Glycolylation of the nucleotide precursors of peptidoglycan biosynthesis of Mycobacterium spp. is altered by drug treatment. J Bacteriol 187: 2341-2347.

Makarov V, Manina G, Mikusova K, Mollmann U, Ryabova O, Saint-Joanis B, Dhar N, Pasca MR, Buroni S, Lucarelli AP, et al. 2009. Benzothiazinones kill Mycobacterium tuberculosis by blocking arabinan synthesis. Science 324: 801-804.

Matsuhashi M. 1966. [Biosynthesis in the bacterial cell wall]. Tanpakushitsu Kakusan Koso 11: 875-886.

May JF, Splain RA, Brotschi C, Kiessling LL. 2009. A tethering mechanism for length control in a processive carbohydrate polymerization. Proc Natl Acad Sci 106: 1185111856.

McNeil M, Wallner SJ, Hunter SW, Brennan PJ. 1987. Demonstration that the galactosyl and arabinosyl residues in the cell-wall arabinogalactan of Mycobacterium leprae and Mycobacterium tuberculosis are furanoid. Carbohydr Res 166: 299-308.

McNeil M, Daffe M, Brennan PJ. 1990. Evidence for the nature of the link between the arabinogalactan and peptidoglycan of mycobacterial cell walls. J Biol Chem 265: 18200-18206.

McNeil M, Daffe M, Brennan PJ. 1991. Location of the mycolyl ester substituents in the cell walls of mycobacteria. J Biol Chem 266: 13217-13223.

McNeil MR, Robuck KG, Harter M, Brennan PJ. 1994. Enzymatic evidence for the presence of a critical terminal hexa-arabinoside in the cell walls of Mycobacterium tuberculosis. Glycobiology 4: 165-173.

Meroueh SO, Bencze KZ, Hesek D, Lee M, Fisher JF, Stemmler TL, Mobashery S. 2006. Three-dimensional structure of the bacterial cell wall peptidoglycan. Proc Natl Acad Sci 103: 4404-4409.

Mikusova K, Slayden RA, Besra GS, Brennan PJ. 1995. Biogenesis of the mycobacterial cell wall and the site of action of ethambutol. Antimicrob Agents Chemother 39: 24842489.

Mikusova K, Mikus M, Besra GS, Hancock I, Brennan PJ. 1996. Biosynthesis of the linkage region of the mycobacterial cell wall. J Biol Chem 271: 7820-7828.

Mikusova K, Huang H, Yagi T, Holsters M, Vereecke D, D'Haeze W, Scherman MS, Brennan PJ, McNeil MR, Crick DC. 2005. Decaprenylphosphoryl arabinofuranose, the donor of the D-arabinofuranosyl residues of mycobacterial arabinan, is formed via a two-step epimerization of decaprenylphosphoryl ribose. J Bacteriol 187: 8020-8025.

Mikusova K, Belanova M, Kordulakova J, Honda K, McNeil MR, Mahapatra S, Crick DC, Brennan PJ. 2006. Identification of a novel galactosyl transferase involved in bio- 


\section{L.J. Alderwick et al.}

synthesis of the mycobacterial cell wall. J Bacteriol 188: 6592-6598.

Mills JA, Motichka K, Jucker M, Wu HP, Uhlik BC, Stern RJ, Scherman MS, Vissa VD, Pan F, Kundu M, et al. 2004. Inactivation of the mycobacterial rhamnosyltransferase, which is needed for the formation of the arabinogalactan-peptidoglycan linker, leads to irreversible loss of viability. J Biol Chem 279: 43540-43546.

Minnikin DE. 1982. Lipids: Complex lipids, their chemistry, biosynthesis and roles. In The biology of the mycobacteria (eds. Ratledge C, Stanford J), pp. 95-184. Academic Press, London.

Minnikin DE, Kremer L, Dover LG, Besra GS. 2002. The methyl-branched fortifications of Mycobacterium tuberculosis. Chem Biol 9: 545-553.

Misaki A, Yukawa S. 1966. Studies on cell walls of mycobacteria. II. Constitution of polysaccharides from BCG cell walls. J Biochem (Tokyo) 59: 511-520.

Mohamed YF, Valvano MA. 2014. A Burkholderia cenocepacia MurJ (MviN) homolog is essential for cell wall peptidoglycan synthesis and bacterial viability. Glycobiology 24: $564-576$.

Mohammadi T, van Dam V, Sijbrandi R, Vernet T, Zapun A, Bouhss A, Diepeveen-de Bruin M, Nguyen-Disteche M, de Kruijff B, Breukink E. 2011. Identification of FtsW as a transporter of lipid-linked cell wall precursors across the membrane. EMBO J 30: 1425-1432.

Nassau PM, Martin SL, Brown RE, Weston A, Monsey D, McNeil MR, Duncan K. 1996. Galactofuranose biosynthesis in Escherichia coli K-12: Identification and cloning of UDP-galactopyranose mutase. J Bacteriol 178: 10471052.

Pan F, Jackson M, Ma Y, McNeil M. 2001. Cell wall core galactofuran synthesis is essential for growth of mycobacteria. J Bacteriol 183: 3991-3998.

Panda M, Ramachandran S, Ramachandran V, Shirude PS, Humnabadkar V, Nagalapur K, Sharma S, Kaur P, Guptha S, Narayan A, et al. 2014. Discovery of pyrazolopyridones as a novel class of non-covalent DprE1 inhibitor with potent anti-mycobacterial activity. J Med Chem. 57: 4761-4771.

Parikh A, Verma SK, Khan S, Prakash B, Nandicoori VK. 2009. PknB-mediated phosphorylation of a novel substrate, $\mathrm{N}$-acetylglucosamine-1-phosphate uridyltransferase, modulates its acetyltransferase activity. J Mol Biol 386: $451-464$.

Patru MM, Pavelka MS Jr. 2010. A role for the class A penicillin-binding protein PonA2 in the survival of Mycobacterium smegmatis under conditions of nonreplication. $J$ Bacteriol 192: 3043-3054.

Peng W, Zou L, Bhamidi S, McNeil MR, Lowary TL. 2012. The galactosamine residue in mycobacterial arabinogalactan is $\alpha$-linked. J Org Chem 77: 9826-9832.

Petit JF, Adam A, Wietzerbin-Falszpan J, Lederer E, Ghuysen JM. 1969. Chemical structure of the cell wall of Mycobacterium smegmatis. I. Isolation and partial characterization of the peptidoglycan. Biochem Biophys Res Commun 35: $478-485$.

Plocinski P, Ziolkiewicz M, Kiran M, Vadrevu SI, Nguyen HB, Hugonnet J, Veckerle C, Arthur M, Dziadek J, Cross TA, et al. 2011. Characterization of CrgA, a new partner of the Mycobacterium tuberculosis peptidoglycan polymerization complexes. J Bacteriol 193: 3246-3256.

Prosser GA, de Carvalho LP. 2013a. Kinetic mechanism and inhibition of Mycobacterium tuberculosis D-alanine:D-alanine ligase by the antibiotic D-cycloserine. FEBS J 280: 1150-1166.

Prosser GA, de Carvalho LP. 2013b. Metabolomics reveal Dalanine:D-alanine ligase as the target of D-cycloserine. ACS Med Chem Lett 4: 1233-1237.

Raymond JB, Mahapatra S, Crick DC, Pavelka MS Jr. 2005. Identification of the namH gene, encoding the hydroxylase responsible for the $N$-glycolylation of the mycobacterial peptidoglycan. J Biol Chem 280: 326-333.

Ruiz N. 2008. Bioinformatics identification of MurJ (MviN) as the peptidoglycan lipid II flippase in Escherichia coli. Proc Natl Acad Sci 105: 15553-15557.

Scherman M, Weston A, Duncan K, Whittington A, Upton R, Deng L, Comber R, Friedrich JD, McNeil M. 1995. Biosynthetic origin of mycobacterial cell wall arabinosyl residues. J Bacteriol 177: 7125-7130.

Schleifer KH, Kandler O. 1972. Peptidoglycan types of bacterial cell walls and their taxonomic implications. Bacteriol Rev 36: 407-477.

Schoonmaker MK, Bishai WR, Lamichhane G. 2014. Nonclassical transpeptidases of Mycobacterium tuberculosis alter cell size, morphology, the cytosolic matrix, protein localization, virulence, and resistance to $\beta$-lactams. J Bacteriol 196: 1394-1402.

Seidel M, Alderwick LJ, Birch HL, Sahm H, Eggeling L, Besra GS. 2007a. Identification of a novel arabinofuranosyltransferase AftB involved in a terminal step of cell wall arabinan biosynthesis in Corynebacterianeae, such as $\mathrm{Co}$ rynebacterium glutamicum and Mycobacterium tuberculosis. J Biol Chem 282: 14729-14740.

Seidel M, Alderwick LJ, Sahm H, Besra GS, Eggeling L. 2007b. Topology and mutational analysis of the single Emb arabinofuranosyltransferase of Corynebacterium glutamicum as a model of Emb proteins of Mycobacterium tuberculosis. Glycobiology 17: 210-219.

Shi L, Zhou R, Liu Z, Lowary TL, Seeberger PH, Stocker BL, Crick DC, Khoo KH, Chatterjee D. 2008. Transfer of the first arabinofuranose residue to galactan is essential for Mycobacterium smegmatis viability. J Bacteriol 190: $5248-5255$.

Shirude PS, Shandil R, Sadler C, Naik M, Hosagrahara V, Hameed S, Shinde V, Bathula C, Humnabadkar V, Kumar N, et al. 2013. Azaindoles: Noncovalent DprE1 inhibitors from scaffold morphing efforts, kill Mycobacterium tuberculosis and are efficacious in vivo. J Med Chem 56: 9701-9708.

Sieger B, Schubert K, Donovan C, Bramkamp M. 2013. The lipid II flippase RodA determines morphology and growth in Corynebacterium glutamicum. Mol Microbiol 90: $966-982$.

Skovierova H, Larrouy-Maumus G, Zhang J, Kaur D, Barilone N, Kordulakova J, Gilleron M, Guadagnini S, Belanova M, Prevost MC, et al. 2009. AftD, a novel essential arabinofuranosyltransferase from mycobacteria. Glycobiology 19: 1235-1247.

Stanley SA, Grant SS, Kawate T, Iwase N, Shimizu M, Wivagg C, Silvis M, Kazyanskaya E, Aquadro J, Golas A, et al. 2012. Identification of novel inhibitors of M. tuberculosis 
growth using whole cell based high-throughput screening. ACS Chem Biol 7: 1377-1384.

Stern RJ, Lee TY, Lee TJ, Yan W, Scherman MS, Vissa VD, Kim SK, Wanner BL, McNeil MR. 1999. Conversion of dTDP-4-keto-6-deoxyglucose to free dTDP-4-ketorhamnose by the rmIC gene products of Escherichia coli and Mycobacterium tuberculosis. Microbiology 145: $663-$ 671.

Szczepina MG, Zheng RB, Completo GC, Lowary TL, Pinto BM. 2009. STD-NMR studies suggest that two acceptor substrates for GlfT2, a bifunctional galactofuranosyltransferase required for the biosynthesis of Mycobacterium tuberculosis arabinogalactan, compete for the same binding site. Chembiochem 10: 2052-2059.

Takayama K, Armstrong EL, Kunugi KA, Kilburn JO. 1979. Inhibition by ethambutol of mycolic acid transfer into the cell wall of Mycobacterium smegmatis. Antimicrob Agents Chemother 16: 240-242.

Takayama K, Kilburn JO. 1989. Inhibition of synthesis of arabinogalactan by ethambutol in Mycobacterium smegmatis. Antimicrob Agents Chemother 33: 1493-1499.

Telenti A, Philipp WJ, Sreevatsan S, Bernasconi C, Stockbauer KE, Wieles B, Musser JM, Jacobs WR Jr. 1997. The emb operon, a gene cluster of Mycobacterium tuberculosis involved in resistance to ethambutol. Nat Med 3: $567-$ 570.

Thomas JP, Baughn CO, Wilkinson RG, Shepherd RG. 1961 A new synthetic compound with antituberculous activity in mice: Ethambutol (dextro-2,2' -(ethylenediimino)-di1-butanol). Am Rev Respir Dis 83: 891-893.

Trefzer C, Rengifo-Gonzalez M, Hinner MJ, Schneider P, Makarov V, Cole ST, Johnsson K. 2010. Benzothiazinones: Prodrugs that covalently modify the decaprenylphosphoryl- $\beta$-D-ribose $2^{\prime}$-epimerase DprE1 of Mycobacterium tuberculosis. J Am Chem Soc 132: 13663-13665.

Trefzer C, Skovierova H, Buroni S, Bobovska A, Nenci S Molteni E, Pojer F, Pasca MR, Makarov V, Cole ST, et al. 2012. Benzothiazinones are suicide inhibitors of mycobacterial decaprenylphosphoryl- $\beta$-D-ribofuranose $2^{\prime}$-oxidase DprE1. J Am Chem Soc 134: 912-915.

Trunkfield AE, Gurcha SS, Besra GS, Bugg TD. 2010. Inhibition of Escherichia coli glycosyltransferase MurG and
Mycobacterium tuberculosis Gal transferase by uridinelinked transition state mimics. Bioorg Med Chem 18: 2651-2663.

van Heijenoort J. 2001. Formation of the glycan chains in the synthesis of bacterial peptidoglycan. Glycobiology 11: 25R-36R.

Vollmer W, Holtje JV. 2004. The architecture of the murein (peptidoglycan) in gram-negative bacteria: Vertical scaffold or horizontal layer(s)? J Bacteriol 186: 5978-5987.

Wang F, Sambandan D, Halder R, Wang J, Batt SM, Weinrick B, Ahmad I, Yang P, Zhang Y, Kim J, et al. 2013. Identification of a small molecule with activity against drugresistant and persistent tuberculosis. Proc Natl Acad Sci 110: E2510-E2517.

Weston A, Stern RJ, Lee RE, Nassau PM, Monsey D, Martin SL, Scherman MS, Besra GS, Duncan K, McNeil MR. 1997. Biosynthetic origin of mycobacterial cell wall galactofuranosyl residues. Tuber Lung Dis 78: 123-131.

Wheatley RW, Zheng RB, Richards MR, Lowary TL, Ng KK. 2012. Tetrameric structure of the GlfT2 galactofuranosyltransferase reveals a scaffold for the assembly of mycobacterial arabinogalactan. J Biol Chem 287: $28132-$ 28143.

Wietzerbin-Falszpan J, Das BC, Azuma I, Adam A, Petit JF, Lederer E. 1970. Isolation and mass spectrometric identification of the peptide subunits of mycobacterial cell walls. Biochem Biophys Res Commun 40: 57-63.

Wolucka BA, McNeil MR, de Hoffmann E, Chojnacki T Brennan PJ. 1994. Recognition of the lipid intermediate for arabinogalactan/arabinomannan biosynthesis and its relation to the mode of action of ethambutol on mycobacteria. J Biol Chem 269: 23328-23335.

Xin Y, Lee RE, Scherman MS, Khoo KH, Besra GS, Brennan PJ, McNeil M. 1997. Characterization of the in vitro synthesized arabinan of mycobacterial cell walls. Biochim Biophys Acta 1335: 231-234.

Zhang W, Jones VC, Scherman MS, Mahapatra S, Crick D, Bhamidi S, Xin Y, McNeil MR, Ma Y. 2008. Expression, essentiality, and a microtiter plate assay for mycobacterial GlmU, the bifunctional glucosamine-1-phosphate acetyltransferase and $\mathrm{N}$-acetylglucosamine-1-phosphate uridyltransferase. Int J Biochem Cell Biol 40: 2560-2571. 


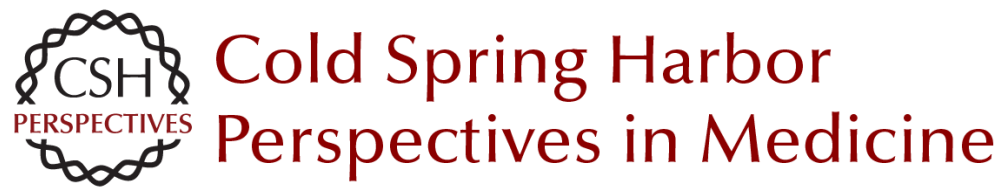

\section{The Mycobacterial Cell Wall---Peptidoglycan and Arabinogalactan}

Luke J. Alderwick, James Harrison, Georgina S. Lloyd and Helen L. Birch

Cold Spring Harb Perspect Med 2015; doi: 10.1101/cshperspect.a021113 originally published online March 27, 2015

\section{Subject Collection Tuberculosis}

Transmission and Institutional Infection Control of Tuberculosis Edward A. Nardell

Innate and Adaptive Cellular Immune Responses

to Mycobacterium tuberculosis Infection Katrin D. Mayer-Barber and Daniel L. Barber

Tuberculosis Comorbidity with Communicable and Noncommunicable Diseases Matthew Bates, Ben J. Marais and Alimuddin Zumla

Host-Directed Therapies for Tuberculosis David M. Tobin

Immunity and Immunopathology in the Tuberculous Granuloma Antonio J. Pagán and Lalita Ramakrishnan

Tuberculosis Drug Development: History and Evolution of the Mechanism-Based Paradigm? Sumit Chakraborty and Kyu Y. Rhee

Genetic Approaches to Facilitate Antibacterial Drug Development Dirk Schnappinger

The Tuberculosis Drug Discovery and Development Pipeline and Emerging Drug Targets Khisimuzi Mdluli, Takushi Kaneko and Anna Upton
Clinical Aspects of Adult Tuberculosis Robert Loddenkemper, Marc Lipman and Alimuddin Zumla

Advances in Diagnostic Assays for Tuberculosis Stephen D. Lawn

Diagnosis and Management of Latent

Tuberculosis Infection

Laura Muñoz, Helen R. Stagg and Ibrahim Abubakar

Mycobacterial Growth Iria Uhía, Kerstin J. Williams, Vahid Shahrezaei, et al.

Multidrug-Resistant Tuberculosis and Extensively

Drug-Resistant Tuberculosis Kwonjune J. Seung, Salmaan Keshavjee and Michael L. Rich

The Mycobacterial Cell Wall--Peptidoglycan and

Arabinogalactan Luke J. Alderwick, James Harrison, Georgina S. Lloyd, et al.

Tuberculosis and HIV Coinfection Judith Bruchfeld, Margarida Correia-Neves and Gunilla Källenius

Imaging in Tuberculosis Jamshed B. Bomanji, Narainder Gupta, Parveen Gulati, et al.

For additional articles in this collection, see http://perspectivesinmedicine.cshlp.org/cgi/collection/ 